\title{
Segmental reflex pathways in spinal shock and spinal spasticity in man
}

\author{
P. ASHBY, M. VERRIER, AND E. LIGHTFOOT \\ From the Neurophysiology Unit, Toronto Western Hospital, Toronto, Canada
}

SYNOPSIS Activity in three segmental pathways was compared in normal subjects, patients with spinal shock, and patients with established spinal spasticity. The Achilles tendon reflex (ATR) was used to estimate transmission in the Ia monosynaptic pathway. Evidence is produced implying that vibration activates motoneurones principally through a polysynaptic pathway. The tonic vibration reflex (TVR) was used to estimate transmission in this Ia polysynaptic pathway. The percentage of the motoneurone pool (M-response) that could be activated by these pathways was used as a measure of transmission. The $\mathrm{H}$ reflex (vibration)/ $\mathrm{H}$ reflex (control) ratio was used as an estimate of the degree of presynaptic inhibition of the Ia monosynaptic pathway. The findings led to the followinge conclusions. (1) In spinal shock presynaptic inhibition is greater than normal, transmission in the Ia monosynaptic pathway is reduced, and in the Ia polysynaptic pathway virtually abolished. (2) Inestablished spasticity presynaptic inhibition is impaired, transmission in the Ia monosynaptic path-o way is increased, but transmission in the Ia polysynaptic pathway never recovers. (3) The failure of presynaptic inhibition associated with spasticity is a gradual process. A hypothesis to explain these $e^{\pi}$ findings is proposed.

Transection of the spinal cord results, initially, in a stage of profound depression of spinal reflex activity ('spinal shock') which is followed, after a variable interval depending on the species, by a stage of exaggerated segmental responses ('spasticity'). Although the features of these stages have been known for many years (Sherrington, 1906; Riddoch, 1917), the underlying neurophysiology is still unclear.

Fusimotor drive may be reduced in spinal shock in man (Weaver et al., 1963), if not in animals (Hunt et al., 1963); the motoneurones become hyperpolarized in animals (Barnes et al., 1962) and their excitability is diminished in man (Diamantopoulos and Olsen, 1967). The depression of segmental activity in spinal shock is generally attributed to loss of supraspinal facilitation-for example, Sherrington (1906) implying that supraspinal influences are, as a whole, facilitatory.

Several abnormalities have been demonstrated

Address for reprints: Dr P. Ashby, Toronto Western Hospital, Toronto, Canada. that could contribute to the exaggerated seg mental responses observed in 'spasticity'. Thus, motoneurones are more excitable (Olsen and Diamantopoulos, 1967), dynamic fusimotor drive may be increased-for example, Dietrichson (1973) - presynaptic inhibition may be reduced (Delwaide, 1973) and Renshaw cell inhibition may be less effective (Veale et al., 1973). These abnormalities are generally attributed to the release of segmental reflex pathways from supraspinal inhibition implying that supraspinal influences are, on the whole, inhibitory. It remains difficult to form a clear hypothesis incorporating these various findings and any new approach would be welcome.

A combination of recently developed methods of testing spinal reflex pathways (Desmedt, 1973) permits a re-examination of these states. In this study, the Achilles tendon reflex (ATR) is used to estimate transmission in the Ia monosynaptic pathway, and the tonic vibration reflex (TVR) to estimate transmission in the Ia polysynaptic pathway to motoneurones. The per- 
TABLE 1

NORMAL SUBJECTS

\begin{tabular}{|c|c|c|c|c|c|c|c|c|}
\hline & & Sex & Age $(y r)$ & $\frac{T V R_{0}}{M} \%$ & $\frac{A T R}{M} \%$ & $\frac{H_{0}}{M} \%$ & $\frac{H v i b}{H} \%$ & $\frac{A T R \text { vib }}{A T R} \%$ \\
\hline $\begin{array}{l}1 \\
2 \\
3 \\
4 \\
5 \\
6\end{array}$ & $\begin{array}{l}\text { H.V. } \\
\text { P.T. } \\
\text { P.B. } \\
\text { B.F. } \\
\text { D.A. } \\
\text { J.D. }\end{array}$ & $\begin{array}{l}\mathbf{F} \\
\mathbf{M} \\
\mathbf{F} \\
\mathbf{M} \\
\mathbf{M} \\
\mathbf{M}\end{array}$ & $\begin{array}{l}25 \\
30 \\
26 \\
40 \\
26 \\
42\end{array}$ & $\begin{array}{l}48 \\
49 \\
33 \\
28 \\
35 \\
51\end{array}$ & $\begin{array}{l}41 \\
28 \\
15 \\
47 \\
23 \\
15\end{array}$ & $\begin{array}{l}41 \\
62 \\
36 \\
79 \\
40 \\
58\end{array}$ & $\begin{array}{l}17 \\
58 \\
11 \\
71 \\
50 \\
52\end{array}$ & $\begin{array}{r}5 \\
7 \\
13 \\
34 \\
30 \\
20\end{array}$ \\
\hline \multicolumn{3}{|c|}{$\begin{array}{l}\text { Mean } \\
\text { SD }\end{array}$} & $\begin{array}{r}31 \cdot 5 \\
7 \cdot 6\end{array}$ & $\begin{array}{r}41 \cdot 7 \\
9 \cdot 8\end{array}$ & $\begin{array}{l}28 \cdot 2 \\
13 \cdot 4\end{array}$ & $\begin{array}{l}52.6 \\
16.6\end{array}$ & $\begin{array}{l}43 \cdot 2 \\
23 \cdot 8\end{array}$ & $\begin{array}{l}18 \cdot 2 \\
12 \cdot 0\end{array}$ \\
\hline
\end{tabular}

centage of the motoneurone pool (M-response) that can be activated by these pathways is used as a measure of transmission. The $H$ reflex (vibration)/H reflex (control) ratio is used to estimate the degree of presynaptic inhibition of the Ia monosynaptic pathway.

\section{METHODS}

Studies were carried out on six normal subjects and 10 patients with recent or remote spinal lesions. Of the patients with spinal lesions, seven were physiologically complete. The other three patients had virtually complete lesions. In all three patients motor function was totally lost below the lesion, but one had a small area in which sensory stimuli could be perceived vaguely on one thigh. The other two had a small patch of preserved touch sensation on one foot. All other sensory modalities were abolished. In each instance the limb with the complete deficit was examined.

Studies were performed with the subject lying prone. The leg to be examined was immobilized in a padded frame with padded clamps gripping the malleoli. The sole of the foot rested against a foot board pivoted at the level of the malleoli. The ankle joint was fixed at $90^{\circ}$.

Square wave electrical stimuli, 1 ms duration, generated by a Grass S 88 stimulator were delivered to the popliteal nerve in the popliteal fossa using bipolar surface electrodes positioned so as to produce a reflex response at the lowest possible threshold and then immobilized with a rubber strap. The stimulator was triggered by a Digital PDP 12 computer pro-

TABLE 2

PATIENTS WITH COMPLETE SPINAL LESIONS

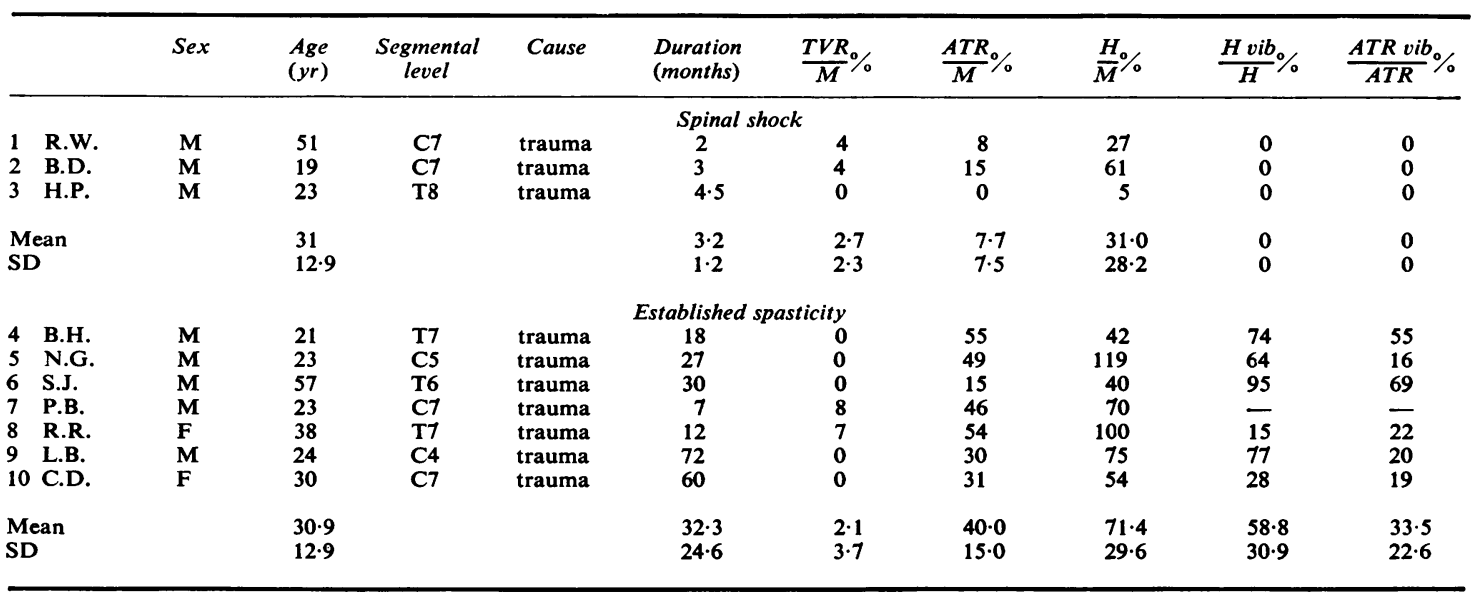


grammed to deliver 10 impulses at random intervals between two and three seconds. The stimulus current was increased in steps until a complete $\mathrm{H}-\mathrm{M}$ recruitment curve had been obtained; a further increase of at least $25 \%$ ensured that a supramaximal $M$ response had been obtained.

The Achilles tendon reflex (ATR) was evoked with supramaximal mechanical stimuli delivered with a tendon hammer that triggered the oscilloscope sweep and the averaging programme. These stimuli were given at random intervals between two and three seconds. The responses were monitored on a Tektronix storage oscilloscope so that responses that were not supramaximal could be rejected. Vibration was applied to the tendo Achillis $1 \mathrm{~cm}$ above its insertion into the calcaneum with a Wahl Jumbo vibrator (frequency $60 \mathrm{~Hz}$; undamped amplitude $3 \mathrm{~mm}$ ).

The compound action potential of the soleus muscle was recorded with $2 \mathrm{~cm}$ diameter disc surface electrodes. The active electrode was placed over the belly of the soleus, in the midline, $2 \mathrm{~cm}$ below the insertions of the medial and lateral heads of gastrocnemius and the reference electrode $8 \mathrm{~cm}$ distally over the tendo Achillis. A $2 \mathrm{~cm}$ square lead plate over the upper gastrocnemius acted as ground.

Action potentials were amplified by a Tektronix (type 2A-60) amplifier, with filter settings $0 \cdot 1 \mathrm{~Hz}$ and $0.1 \mathrm{MHz}$, and monitored on a Tektronix storage oscilloscope. This signal was digitalized $(1,000 / \mathrm{s})$ by the PDP 12 computer and five (mechanically) or 10 (electrically) induced responses were averaged. These responses were plotted with an incremental plotter (Complot 7) and the peak to peak amplitude of the $\mathrm{H}$ or $M$ response and the ATR was measured from the plotting paper.

The force generated by plantar flexion of the foot was measured with a two arm strain gauge connected to the foot plate, activated by a 7PIC low level DC preamplifier and recorded on a Grass Model 7B ink writing polygraph.

When the experimental conditions appeared stable, the following procedure was adopted. Three or more supramaximal electrical stimuli were delivered to the popliteal nerve to elicit a maximum contraction of the soleus muscle. The developed tension was recorded on the polygraph. Vibration was applied to the Achilles tendon to evoke a tonic vibration reflex (TVR). The vibration was maintained until the developed tension had reached a plateau. This was repeated three or more times. Next the H-M recruitment curve was recorded. At each stimulus level control runs and runs with vibration were alternated. After each one run with vibration 90 seconds elapsed to avoid the long lasting depression of the monosynaptic reflex (Arcangel et al.,
1971). Finally the ATR was averaged. Control runs alternated with runs with vibration. In this instance the vibration was applied to the lateral border of the soleus muscle.

The compound action potential produced by a supramaximal stimulus of the popliteal nerve was assumed to represent the activity of $100 \%$ of the soleus motor units. The compound action potential of the ATR could be compared with this value and
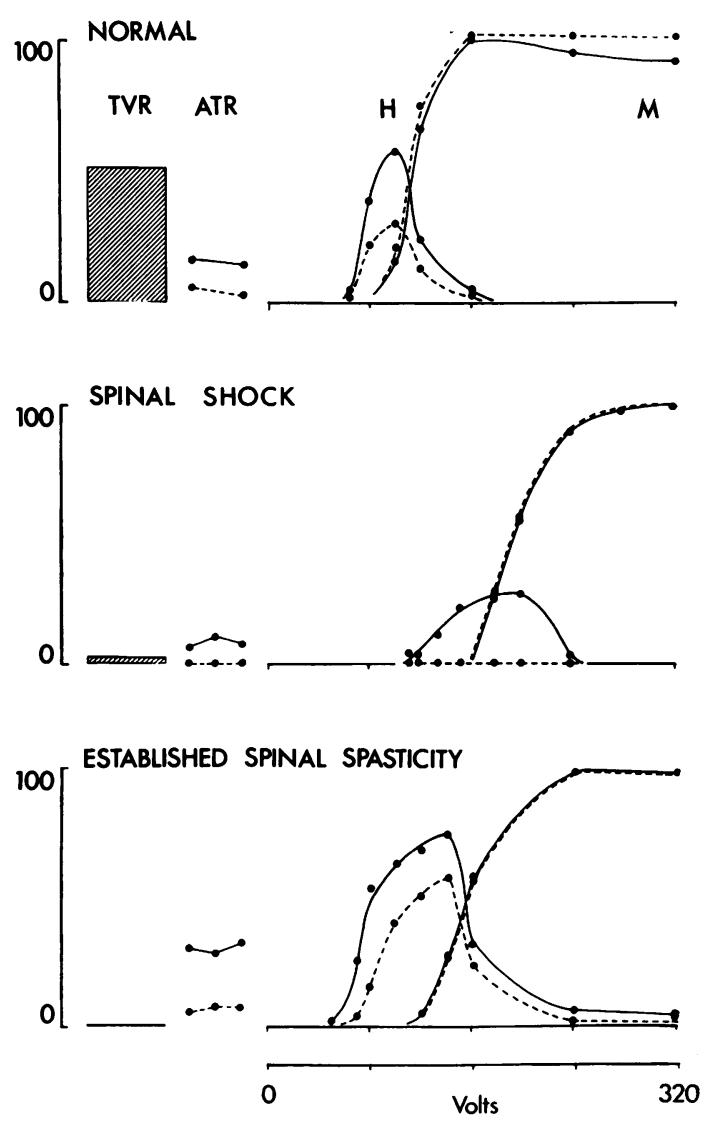

FIG. 1. Data on three subjects. The tonic vibration reflex (TVR), Achilles tendon reflex (ATR), and $H$ reflex $(\mathrm{H})$ are expressed as a percentage of the motoneurone pool of soleus $(\mathrm{M})$. The dotted line represents the $A T R, H$, and $M$ responses during vibration. In the normal subject, vibration activates almost $50 \%$ of the motoneurone pool, the ATR $20 \%$. Vibration reduces the $H$ reflex by about half. In spinal shock the TVR and $A T R$ are reduced and the $H$ reflex is completely inhibited by vibration. In established spasticity the ATR is increased but the TVR remains absent. Vibration now has little effect on the $H$ reflex. 


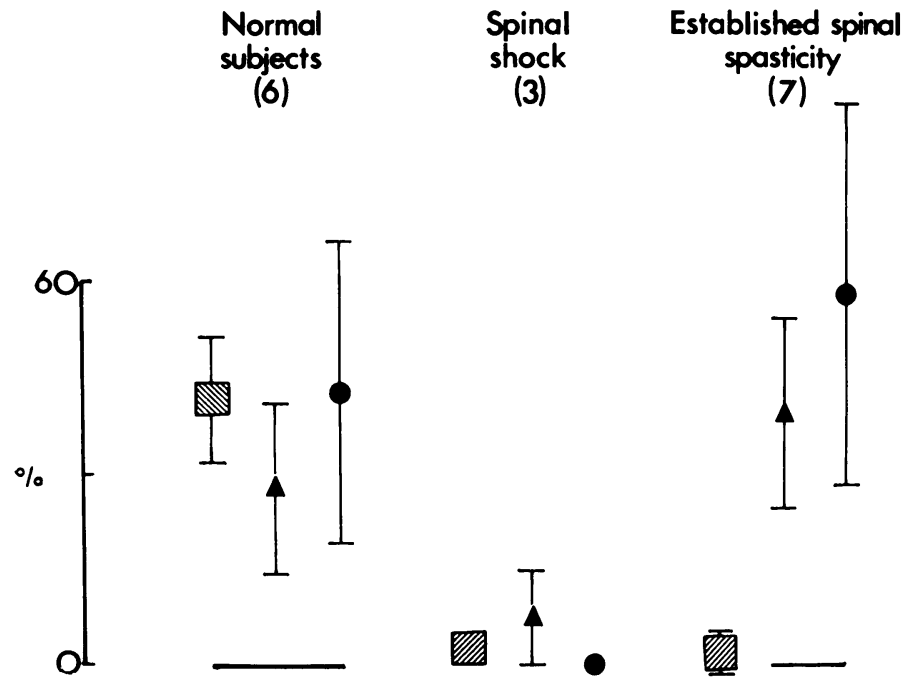

FIG. 2. The tonic vibration reflex (TVR), Achilles tendon reflex (ATR) expressed as a percentage of the motoneurone pool of soleus. The $H$ reflex with vibration is expressed as a percentage of the control $H$ reflex. In the three subjects with spinal shock the TVR and ATR are significantly reduced. The $H$ reflex is always completely inhibited by vibration. In seven patients with established spasticity the ATR is increased but the TVR remains virtually absent. There is less inhibition of the $H$ reflex by vibration in spasticity (means and standard deviations). 2 : $T V R / M, \triangle: A T R /$ $M, \bigcirc: H v i b / H$.

the ATR expressed as a percentage of the motoneurone pool activated by the Ia monosynaptic pathway. The tension resulting from supramaximal electrical stimuli of the popliteal nerve was assumed to represent the activity of $100 \%$ of soleus motor units. By comparing the tension produced by the TVR with that developed by supramaximal stimulation of the popliteal nerve, the TVR could also be expressed as a percentage of the motoneurone pool reflexly activated. The ratio of the maximum $\mathbf{H}$ (vibration) to the maximum $\mathrm{H}$ (control) was taken to indicate the extent of presynaptic inhibition of the Ia monosynaptic pathway induced by vibration. Student's $t$ test and the correlation coefficient were used to compare results in normal subjects, patients with spinal shock, and those with established spasticity.

\section{RESULTS}

NORMAL SUBJECTS In six normal subjects (Table 1) the mean ATR/M ratio was $28 \cdot 2 \%$. Vibration resulted in a slowly augmenting TVR with a mean plateau tension that was $41.7 \%$ of the tension resulting from supramaximal stimulation of the motor nerve. The $\mathrm{H}$ vibration/ $\mathrm{H}$ control ratio was quite variable, the mean being $43 \cdot 1 \%$.

SPINAL SHOCK Three patients who had suffered physiologically complete transection of the cord were examined in the stage of spinal shock (Table 2, Fig. 1, 2). All had profound hypotonia and even rapid passive movements at the knee or ankle did not elicit a reflex response. Painful stimulation of the toes resulted in a feeble reflex contraction of the hamstrings. The tendon jerks were obtainable, but the mean ATR/M ratio was $7 \cdot 7 \%$. Vibration of the tendo Achillis produced a minimal alteration in muscle tension (mean $2.7 \%$ of the tension resulting from supramaximal stimulation of the motor nerve). Even though a large $\mathrm{H}$ reflex (up to $61 \%$ of the $M$ response) could be evoked in spinal shock, vibration always completely suppressed the $\mathrm{H}$ reflex in every patient.

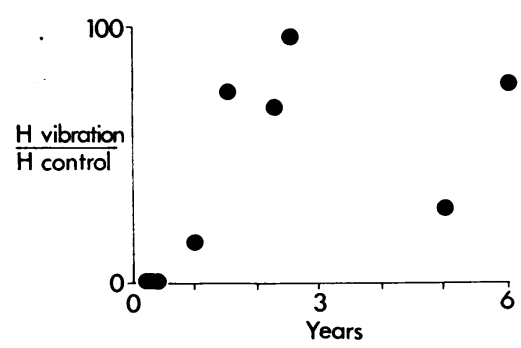

FIG. 3. Relationship between the suppression of the $H$ reflex by vibration and the duration of the neurological deficit in nine patients with complete, or virtually complete, spinal lesions. The inhibitory mechanism appears to fail gradually over a three year period. 
ESTABLISHED SPASTICITY In the seven patients with established spasticity (characterized by exaggerated stretch reflexes, clonus, extensor and flexor spasms, and brisk tendon reflexes), the mean ATR/M ratio was $40 \%$ (Fig. 2). Vibration of the tendo Achillis produced a minimal increase in tension only in patients 7 and 8 both of whom had small areas of preserved sensation. The mean increment of tension was $2 \cdot 1 \%$ of the tension resulting from supramaximal stimulation of the motor nerve. Patients 8 and 10 responded to the vibratory stimulus with a phasic spike resembling the ATR but this could not be related to the amplitude of the ATR or to any other parameters in these patients. Muscle vibration was less effective in suppressing the $H$ reflex in patients with spasticity. The $\mathrm{H}$ vibration/H control ratio had considerable variation with a mean of $58.8 \%$.

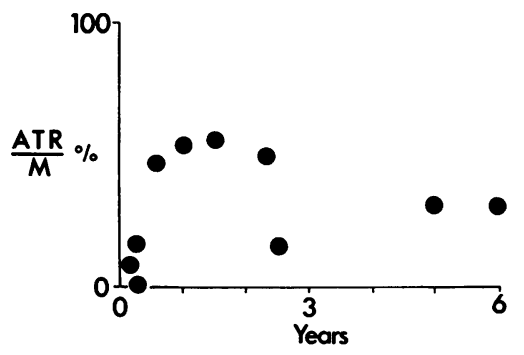

FIG. 4. Relationship between the Achilles tendon reflex (ATR), expressed as a percentage of the total soleus motoneurone pool, and the duration of the neurological deficit in nine patients with complete, or virtually complete, spinal lesions. The ATR reaches its maximum amplitude within one year.

The $\mathbf{H}$ vibration/ $\mathbf{H}$ control ratio appeared to increase gradually over a three year period (Fig. 3 ). By contrast, recovery of the ATR appeared to occur more rapidly. The maximum ATR was reached within one year (Fig. 4), but several patients who had established spasticity for a longer period had ATR's of lower amplitude. This could represent the effects of a superimposed pressure palsy. Two patients with established spasticity were not included in the series because no ATR or $\mathrm{H}$ reflex could be obtained. In one of these (in whom the opportunity arose), needle electrode examination of the soleus muscle revealed widespread fibrillation potentials and positive sharp waves.

The suppression of the $\mathrm{H}$ reflex by vibration is not simply related to the amplitude of the reflex response. Total suppression of the large $\mathrm{H}$ reflex was observed in spinal shock-for example, patient 2-and poor suppression of a small $\mathrm{H}$ reflex was seen in established spasticity-for example, patient 6 . Furthermore, there was no correlation between amplitude of the $\mathrm{H}$ reflex and its degree of suppression. There was no clear relationship between the ATR and the $H$ vibration/H control ratio. Suppression of the ATR and the $\mathrm{H}$ reflex by vibration was similar (correlation coefficients $0.775, P>0.001$ ), but suppression of the ATR was greater (slope of regression line 0.48 ), possibly because the vibration had to be applied to the lateral part of the soleus muscle during elicitation of the tendon jerk (Eklund 1971). There was no correlation between the level of the lesion and the magnitudes of the TVR/M, ATR/M, or $H$ vibration/H controlo ratio.

\section{DISCUSSION}

The $\mathrm{H}$ reflex has not proved to be a reliabl means of comparing the excitability of seg mental reflex pathways in different subjects. This is because the amplitude of the $\mathrm{H}$ reflex depends, in part, on the anatomical disposition of the sensory and motor fibres of the popliteal nerve. For example, if the electrode placement is such that early recruitment of the motor fibres occurs the antidromic volley in the motor nerve will collide with the descending reflex response and this will result in a small $\mathrm{H} / \mathrm{M}$ ratio regardless of the true excitability of the monosynaptic arc. In this study large $\mathrm{H} / \mathrm{M}$ ratios were obtained in some patients with spinal shock and there was no statistical difference between the $\mathrm{H} / \mathrm{M}$ ratio of the normal subjects, those with spinal shock, and those with spasticity. Weaver et al. (1963), and Diamantopoulos and Olsen (1967) also found large $\mathrm{H}$ reflexes in spinal shock and, although Dietrichson (1973) and Angel and Hoffmann (1963) found the $H / M$ ratio was greater in spastic than in normal limbs, the overlap was considerable.

The ATR is not subject to the unwanted 
variation affecting the $\mathrm{H}$ reflex and is, therefore, likely to be a more reliable measure of the excitability of the monosynaptic reflex arc. The tendon tap will excite other afferent nerve fibres -for example, group 2 afferent fibres-but these can be disregarded as only the Ia afferent fibres make monosynaptic connection with the anterior horn cell. The ATR/M ratio may be used to indicate the proportion of the motoneurone pool that is activated by this Ia monosynaptic pathway but certain errors could be introduced by using this ratio. For example, the motor units evoked reflexly may not be from the same motoneurone pool as those activated by direct stimulation of the motor nerve, and the reflex compound action potential may be more dispersed and of slightly lower amplitude because of its longer latency. When the recording electrodes are placed close together over the soleus the compound action potential of the ATR always closely resembles that of the equivalent M-response, so these effects are considered to be minimal. Activity in this Ia monosynaptic pathway was shown to be depressed in spinal shock and increased in spasticity. This is a common clinical finding and has been documented previously by Weaver et al. (1963) and by Dietrichson (1973).
There is evidence to support the contention that the TVR results from activity in a 'Ia polysynaptic pathway'. The primary spindle ending is considered to be the receptor whose excitation leads to the TVR (Matthews, 1966). These endings are the most sensitive to vibration in the cat (Brown et al., 1967) and can be activated easily by vibration in man (Hagbarth, 1973). The Golgi tendon organs and secondary spindle endings are much less sensitive to vibration and are unlikely to contribute to the TVR as activity in their afferent nerve fibres results in inhibition of extensor motoneurones (Burke et al., 1971); Pacinian corpuscles respond optimally to higher frequencies (Sato, 1961). Burke et al. (1972) found that the TVR of an extensor muscle could be potentiated either by increasing muscle length or by the Jendrassic manoeuvre but that the effect of the Jendrassic manoeuvre diminished as the muscle length increased, suggesting that the TVR depends on the spindle and on the primary rather than the secondary endings. In man the Ia afferent barrage is capable of producing a slowly augmenting reflex muscular contraction, with asynchronous firing of motoneurones, during which the Ia monosynaptic reflex arc may be suppressed completely. Homma et al. (1973) have shown that vibration produces both a
NORMAL

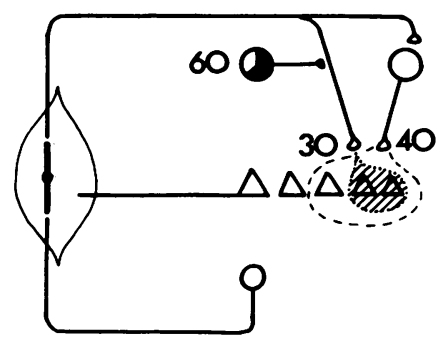

SPINAL SHOCK

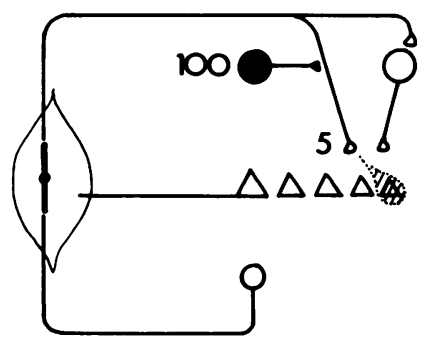

SPASTICITY

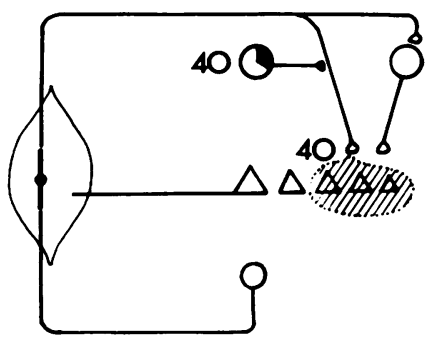

FIG. 5. Postulated activity in reflex pathways in normal subjects, patients with spinal shock and established spasticity. $\triangle$ : Motoneurone pool of soleus, $\bigcirc:$ gamma motoneurone, $\bigcirc$ : interneurone responsible for presynaptic inhibition. In normal subjects presynaptic inhibition can block $60 \%$ of the activity in the monosynaptic pathway. The Ia monosynaptic circuit activates $30 \%$ of the motoneurone pool and the Ia polysynaptic circuit $40 \%$ of the motoneurone pool. In spinal shock presynaptic inhibition is increased. The Ia monosynaptic circuit now activates only $5 \%$ of the motoneurone pool. The Ia polysynaptic circuit, lacking supraspinal support, cannot activate the motoneurone pool. In established spasticity the presynaptic inhibitory mechanism is less effective. The Ia monosynaptic pathway now activates $40 \%$ of the motoneurone pool. The Ia polysynaptic circuit, lacking supraspinal support, still cannot activate the motoneurone pool. (Values derived from Fig. 2.) 
direct and an 'augmentative' excitatory postsynaptic potential in motoneurones, the latter attributable to a polysynaptic pathway. Drugs that block polysynaptic pathways can abolish the TVR leaving the monosynaptic reflex unchanged (De Gail et al., 1966) and spinal transection has a similar differential effect (Lance et al., 1973). Although the TVR must have a monosynaptic component, it appears likely that it depends principally on a Ia polysynaptic pathway such as that demonstrated by Tsukahara and Ohye (1964). Since the monosynaptic reflex but not the TVR is inhibited by vibration, the polysynaptic pathway may be considered to be relatively unaffected by presynaptic inhibition.

Certain errors could be introduced by using a TVR tension/maximum $M$ tension ratio to indicate the proportion of the motoneurone pool activated by vibration. For example, the tension resulting from synchronous discharge of motor units may be somewhat higher than expected from the sum of its components (Merton, 1954) but this effect is likely to be small. The motor units recruited by the Ia barrage may not be from the same motoneurone pool as those activated by supramaximal stimulation of the motor nerve but they are likely to be the same as those recruited by the Ia volley of the ATR and this effect has been considered negligible. Vibration could spread through the limb and evoke a reflex contraction of antagonist muscles, producing a falsely low tension. However, Hagbarth (1973) has indicated that vibration is not a potent stimulus for the spindles of antagonist muscles especially when they are slack. Finally, as the relationship between the amplitude of the compound action potential and the developed tension is approximately linear, it appeared justifiable to use the ratio of the action potentials and the ratio of the developed tensions as parallel estimates of the proportion of the motoneurone pool activated.

The TVR was virtually abolished by spinal cord transection and did not reappear even when spasticity developed. These findings are in accordance with previous observations in patients with complete spinal lesions (Lance et al., 1973), and may be attributed to loss of supraspinal support (Gillies et al., 1971). A small TVR was seen in two of the spastic patients both of whom may have had incomplete lesions. The absence of the
TVR when the ATR is exaggerated implies considerable independence of their central pathways, since fusimotor drive and the excitability of the motoneurone pool are common factors.

Muscle vibration causes inhibition of the monosynaptic reflex in animals and in man (Lance et al., 1973). This effect has been attributed to presynaptic inhibition, since it can be blocked by picrotoxin, is accompanied by depolarization of the Ia nerve terminals, and can occur while the excitability of the motoneurones to direct stimulation is unchanged (Gillies et al., 1969; Barnes and Pompeiano, 1970). In man the evidence that the effect is presynaptic is less direct but the inhibition cannot be attributed to occlusion in the Ia pathway (Lance et al., 1973) and the excitability of the motoneurones to other inputs is unchanged (Delwaide, 1973). This inhibitory mechanism appears to be enhanced in spinal shock.

Ruch and Watts (1934) documented the increase in forelimb tone in a decerebrate animal after transection of the thoracic spinal cordo implying the existence of a spinal inhibitoryo mechanism active in the acute preparation. Liddell (1934) reported that stimulation of the sciatic nerve was capable of producing a pro- 8 longed inhibition of the quadriceps mono synaptic reflex during the stage of spinal shock but not thereafter. Van Harreveld (1940) found that spinal shock could be curtailed by asphyxia of the isolated portion of the cord and postulated that the depressed reflex excitability of this state could depend on the dominance of an inhibitory mechanism. The release of an inhibitory process principally affecting the monosynaptic pathway could explain these findings, as well as the paradoxical earlier recovery of the polysynaptic flexion reflex before the monosynaptic tendon jerk (Riddoch, 1917; Weaver et al., 1963). It is therefore proposed that the enhanced presynaptic inhibition demonstrated in spinal shock makes a significant contribution to the clinical features of this state.

Previous authors have found that vibration is less effective in producing inhibition of the monosynaptic reflex in cerebral (Delwaide, 1973) and spinal (Burke and Ashby, 1972; Ashby and White, 1973) spasticity, Delwaide has proposed that the loss of presynaptic inhibition is one of the most important derangements in spasticity. 
The inhibitory mechanism appears to fail gradually over three years. This may account for the wide variation in presynaptic inhibition seen in a miscellaneous group of spastic patients. The gradual failure raises the possibility that a rearrangement of spinal cord circuits is occurring. For example, there may be sprouting of Ia dorsal root fibres making synapses, not equipped with presynaptic inhibitory terminals, directly upon motoneurones (McCouch et al., 1958). The amplitude of the ATR increases more rapidly than could be accounted for simply by the failure of presynaptic inhibition. It then decreases again. The rapid increase may be determined by additional factors such as increasing fusimotor drive. The subsequent decrease could be explained by a cumulative likelihood of sciatic pressure palsy (Cooper and Sherrington, 1932; Landau and Clare, 1959; Weaver et al., 1963).

It is possible to construct a hypothesis based on the above data (Fig. 5). It is postulated that the motoneurone pool may be activated by a monosynaptic pathway which is subject to presynaptic inhibition and a polysynaptic pathway which is not, and that the interneurones of the polysynaptic pathway require supraspinal facilitation. A tendon tap excites the motoneurone pool via the Ia monosynaptic pathway. The proportion of the motoneurone pool activated by the mechanical stimulus will depend on the level of fusimotor drive, the extent of presynaptic inhibition and the excitability of the motoneurone pool. In normal subjects with the ankle at $90^{\circ}$ a supramaximal tendon tap will excite about $30 \%$ of the motoneurone pool. Vibration applied to the tendon activates the motoneurone pool through the Ia polysynaptic (and monosynaptic) lines. The polysynaptic component will depend on the level of fusimotor drive, the excitability of the motoneurone pool, and the excitability of the interneurone pathway. Any monosynaptic component will depend on the same factors as the ATR. In normal subjects with the ankle at $90^{\circ}$ vibration of the type used in this study activates about $40 \%$ of the motoneurone pool. The $\mathrm{H}$ vibration/H control ratio provides an estimate of the possible potency of presynaptic inhibition. In normal subjects, using the technique described in this study, blocking of about $60 \%$ of the traffic in the monosynaptic line is possible. It is postulated that this value is reflected in the 'resting level' of presynaptic inhibition.

In spinal shock the presynaptic inhibitory mechanism appears to be capable of blocking all of the traffic in the monosynaptic line. The Ia monosynaptic pathway excites only $5 \%$ of the motoneurone pool. This may be attributed to depressed fusimotor drive (Weaver et al., 1963), an increase in presynaptic inhibition (demonstrated in this study), and a decrease in the excitability of the motoneurone (Barnes et al., 1962; Diamantopoulos and Olsen, 1967). The Ia polysynaptic pathway is incapable of exciting the motoneurone pool. This may be attributed to the loss of vestibulo-spinal facilitation of interneurones (Gillies et al., 1971).

In established spasticity the presynaptic inhibitory mechanism is less effective than normal. The Ia monosynaptic pathway now excites about $40 \%$ of the motoneurone pool. This could be due to an increase in fusimotor drive (Dietrichson, 1973), but Delwaide (1973) has suggested that the decrease in presynaptic inhibition may be one of the most important factors. Even though the monosynaptic pathway is hyperactive the Ia polysynaptic pathway still appears incapable of exciting the motoneurone pool, suggesting that supraspinal facilitation of interneurones is of prime importance for the transmission of activity in this pathway.

The authors are grateful to Dr A. T. Jousse and Dr W. O. Geisler of Lyndhurst Lodge Hospital for permission to study patients under their care, to the Audio-Visual Department of the Toronto Western Hospital for preparing the photographs and to Mrs E. Bailey for the preparation of the manuscript.

\section{REFERENCES}

Angel, R. W., and Hofmann, W. W. (1963). The H reflex in normal, spastic, and rigid subjects. Archives of Neurology, 8, 591-596.

Arcangel, C. S., Johnston, R., and Bishop, B. (1971). The Achilles tendon reflex and the $\mathrm{H}$-response during and after tendon vibration. Physical Therapy, 51, 889-905.

Ashby, P., White, D. G. (1973). 'Presynaptic' inhibition in spasticity and the effect of $\beta$ (4-chlorophenyl)GABA. Journal of the Neurological Sciences, 20, 329-338.

Barnes, C. D., Joynt, R. J., and Schottelius, B. A. (1962). Motoneurone resting potentials in spinal shock. American Journal of Physiology, 203, 1113-1116.

Barnes, C. D., and Pompeiano, O. (1970). Inhibition of monosynaptic extensor reflex attributable to presynaptic depolarization of the group Ia afferent fibers produced by vibration of flexor muscle. Archives Italiennes de Biologie, 108, 233-258. 
Brown, M. C., Engberg, I., and Matthews, P. B. C. (1967). The relative sensitivity to vibration of muscle receptors of the cat. Journal of Physiology, 192, 773-800.

Burke, D., Andrews, C., and Ashby, P. (1971). Autogenic effects of static muscle stretch in spastic man. Archives of Neurology, 25, 367-372.

Burke, D., Andrews, C. J., and Lance, J. W. (1972). Tonic vibration reflex in spasticity, Parkinson's disease, and normal subjects. Journal of Neurology, Neurosurgery, and Psychiatry, 35, 477-486.

Burke, D., and Ashby, P. (1972). Are spinal 'presynaptic' inhibitory mechanisms suppressed in spasticity? Journal of the Neurological Sciences, 15, 321-326.

Cooper, S., and Sherrington, C. S. (1932). Degeneration of peripheral nerves after spinal transection in the monkey. Journal of Physiology, 77, 18-19P.

De Gail, P., Lance, J. W., and Neilson, P. D. (1966). Differential effects on tonic and phasic reflex mechanisms produced by vibration of muscles in man. Journal of Neurology, Neurosurgery, and Psychiatry, 29, 1-11.

Delwaide, P. J. (1973). Human monosynaptic reflexes and presynaptic inhibition. In New Developments in Electromyography and Clinical Neurophysiology, vol. 3, pp. 508522. Edited by J. E. Desmedt. Karger: Basel.

Desmedt, J. E. (ed.) (1973). New Developments in Electromyography and Clinical Neurophysiology, vol. 3. Human Reflexes. Pathophysiology of Motor Systems. Karger: Basel.

Diamantopoulos, E., and Olsen, P. Z. (1967). Excitability of motoneurones in spinal shock in man. Journal of Neurology, Neurosurgery, and Psychiatry, 30, 427-431.

Dietrichson, P. (1973). The role of the fusimotor system in spasticity and parkinsonian rigidity. In New Developments in Electromyography and Clinical Neurophysiology, vol. 3, pp. 496-507. Edited by J. E. Desmedt. Karger: Basel.

Eklund, G. (1971). On muscle vibration in man; an amplitudedependent inhibition, inversely related to muscle length. Acta Physiologica Scandinavica, 83, 425-426.

Gillies, J. D., Burke, D., and Lance, J. W. (1971). Tonic vibration reflex in the cat. Journal of Neurophysiology, 34, 252-262.

Gillies, J. D., Lance, J. W., Neilson, P. D., and Tassinari, C. A. (1969). Presynaptic inhibition of the monosynaptic reflex by vibration. Journal of Physiology, 205, 329-339.

Hagbarth, K.-E. (1973). The effect of muscle vibration in normal man and in patients with motor disorders. In New Developments in Electromyography and Clinical Neurophysiology, vol. 3, pp. 428-443. Edited by J. E. Desmedt. Karger: Basel.

Homma, S., Kanda, K., Mizote, M. (1973). Role of monoand polysynaptic reflex arcs during stretch reflex. (Abstract.)
Electroencephalography and Clinical Neurophysiology, 34, 799.

Hunt, R. S., Meltzer, G. E., and Landau, W. M. (1963) Fusimotor function. Part I. Spinal shock of the cat and the monkey. Archives of Neurology, 9, 120-126.

Lance, J. W., Burke, D., and Andrews, C. J. (1973). The reflex effects of muscle vibration. In New Developments in Electromyography and Clinical Neurophysiology, vol. 3, pp. 444-462. Edited by J. E. Desmedt. Karger: Basel.

Landau, W. M., and Clare, M. H. (1959). The plantar reflex in man, with special reference to some conditions where the extensor response is unexpectedly absent. Brain, 82, 321-355.

Liddell, E. G. T. (1934). Spinal shock and some features in isolation-alteration of the spinal cord in cats. Brain, 57, 386-400.

McCouch, G. P., Austin, G. M., Liu, C. N., and Liu, C. Y. (1958). Sprouting as a cause of spasticity. Journal of Neurophysiology, 21, 205-216.

Matthews, P. B. C. (1966). The reflex excitation of the soleus muscle of the decerebrate cat caused by vibration applied to its tendon. Journal of Physiology, 184, 450-472.

Merton, P. A. (1954). Interaction between muscle fibres in a twitch. Journal of Physiology, 124, 311-324.

Olsen, P. Z., and Diamantopoulos, E. (1967). Excitability of spinal motor neurones in normal subjects and patients with spasticity, Parkinsonian rigidity, and cerebellaf hypotonia. Journal of Neurology, Neurosurgery, and Psychiatry, 30, 325-331.

Riddoch, G. (1917). The reflex functions of the completely divided spinal cord in man, compared with those associated with less severe lesions. Brain, 40, 264-402.

Ruch, T. C., and Watts, J. W. (1934). Reciprocal changes in reflex activity of the fore limbs induced by post-brachia 'cold-block' of the spinal cord. American Journal of Physiology, 110, 362-375.

Sato, M. (1961). Response of Pacinian corpuscles to sinu용 soidal vibration. Journal of Physiology, 159, 391-409.

Sherrington, C. S. (1906). The Integrative Action of the Ner vous System. Yale University Press: New Haven.

Tsukahara, N., and Ohye, C. (1964). Polysynaptic activation of extensor motoneurones from group Ia fibres in the cat spinal cord. Experientia, 20, 628-629.

Van Harreveld, A. (1940). On spinal shock. American Journal of Physiology, 129, 515-523.

Veale, J. L., Rees, S., and Mark, R. F. (1973). Renshaw cell activity in normal and spastic man. In New Developments in Electromyography and Clinical Neurophysiology, vol. 3, pp. 523-537. Edited by J. E. Desmedt. Karger: Basel.

Weaver, R. A., Landau, W. M., and Higgins, J. F. (1963). Fusimotor function. Part 2. Evidence of fusimotor depression in human spinal shock. Archives of Neurology, 9, 127132. 